\title{
GIS and Hydrological Model Based Hydropower Potential Assessments of Temcha Watershed
}

\author{
Walelgn Dilnesa \\ Lecture in DMU, IOT, and Hydraulic \&water Resources Engineering Ac/program
}

\begin{abstract}
Hydropower is one of the major and sustainable energy production centers across the world. Energy production has several challenges and uncertainty to alleviate poverty in our country. The main aim of this study was selecteding the hydropower potentials of Temcha watershed with integrated approaches of using GIS and hydrological models (SWAT). For the hydropower potential selection, it was used weather (metrological), hydrological and geospatial data. The result shows that a high discharge amount with a corresponding head has been identified in the upper course of the river and its associated values $300 \mathrm{~m} 3 /$ year. In the middle course of the river, the power potential would be $126 \mathrm{MWmw} / \mathrm{year}$. Generally, the overall hydropower potentials of Temcha watershed were $2500 \mathrm{MWmw} / \mathrm{year}$.
\end{abstract}

Keywords :- hydropower, SWAT, GIS, Temcha watershed

DOI: $10.7176 / \mathrm{JETP} / 10-5-02$

Publication date:September $30^{\text {th }} 2020$

\section{Introduction}

Urbanization, economic development, Industrialization and rapid increase in population growth haveraised the demand for power generation manifolds. A hydropower project generates electricity from the available flow of the river. Around $16 \%$ of the world's energy production and over $80 \%$ of the world's renewable energy is generated through hydropower sector (Mathi and Desmukh, 2016). Ethiopia has a vast hydropower potential, which is estimated to be about 15,000 - 30,000 MW. So far very little percentage (less than 2\%) of the vast potential has been harnessed. In order to develop this vast potential of power several projects have been initiated to generate more and more hydroelectric power. Some 300 hydropower plant sites in the whole eight river basins of the country with a total technical power potential of $159,300 \mathrm{Gwh} /$ year have been identified. Out of these potential sites, 102 are large scale (more than $60 \mathrm{MW}$ ) and the rest are small (less than $40 \mathrm{MW}$ ) and medium scale (40-60 MW) hydropower plant sites.

Flows in many rivers vary considerably during a year. In storage based hydropower projects, a reservoir of water (or potential energy) created behind a dam is used to regulate the inflows and generate energy in accordance with demands. There can be opposition to storage projects from social and environmental groups, due to submergence of forests or places of importance, displacement of population, and adverse impacts on biotic life in rivers.

However, hydropower projects can generate energy with minimal or negligible damage to the environment, though they also have limited benefits. Correct assessment of hydropower potential at a site requires realistic information on topography (particularly elevation) and flows followed by careful analysis of these data. Recent advances in remote sensing (RS), geographic information system (GIS) and hydrological modeling provide realistically, up-to-date and useful information for the assessment of hydropower potential. The combination of GIS and RS techniques provides a powerful tool for studying hydrology in watersheds and also for the assessment of hydropower potential.

Therefore, the aim of this study too, to identify the hydropower potential sites of Temcha watershed. The application of the SWAT hydrological model to assess the temporal and spatial variability of hydropower potential in the Temcha watershed in the upper Blue Nile basin. The assessment of the head, site selection, and simulation of flow at each selected site was carried out using the SWAT model. The SWAT model generates stream network characteristics, the length of the river, and elevation difference for each stream within the watershed boundary. The model has provision for addition or deletion of outlets and inlets by user intervention, which affects the delineation and number of sub-watersheds created by the model, and this facility was utilized in assessing the head variation along the river, by placing sub-basin outlets at different locations.

\section{Methodlogy}

\subsection{Study area}

Hydroelectric power is the cheapest source of power whenever the natural resources are readily available. Ethiopia has plenty of favorable sites where hydroelectric power can be economically generated(Deudney, 1981). The exploitation and development of these untapped hydropower resources of the country need careful planning (short and long term), proper timing, coordinated efforts among all relevant government bodies, technical assistance, and most of all financial resources in order to transform the hydropower potentials into reality. 
The wealth of experiences gathered during the reconnaissance studies, pre-feasibility studies and feasibility studies of all the hydropower potential sites within Tekeze, Gojeb and Abbay River Basin would, no doubt, very much facilitate and benefit all concerned bojies and need to be recorded and documented for ease of reference in future use for projects coming in the pipe line(Bartle, 2002). This is a very important aspect that needs to be given special attention. Temcha watershed has one of the tributaries of upper blue nile basin, located in Amhara region in Dembecha town district. The watershed area has annual flow/perennial river and a gauged station of its stream flow. The area has highland regions its most appropriate for harnessing more small hydropower potentails and it's the discharge capability also suitable for energy production. The manin things is that where is the suitable site for hydropower developments and identify the specific amounts of water potentails.

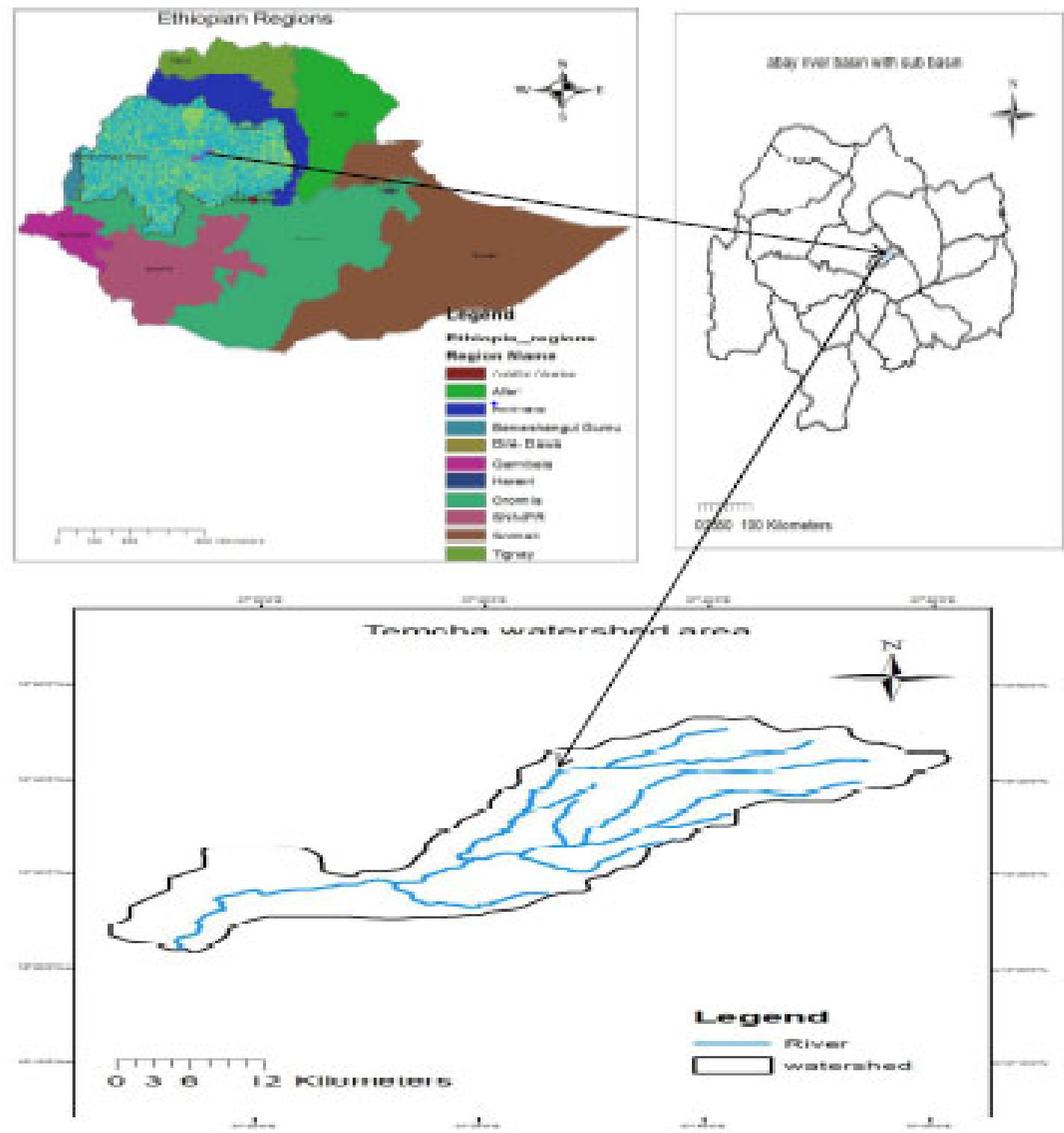

Figure 2.1 location of the study area

\subsection{Input data}

Table 2.1 data sources

\begin{tabular}{|l|l|}
\hline data type & source \\
\hline Land use/cover & USGS \\
\hline Soil & FAO \\
\hline Metrological data & NEMA of ethiopia \\
\hline Stream flow & Ministry of irrigation, electricity and water resources of Ethiopia \\
\hline DEM & usgs \\
\hline
\end{tabular}




\subsection{Data analysis}

The identification of hydropower potential sites on Temcha river flows in the upper Blue Nile basin was examined through simulations using the soil and water assessment tool (SWAT) and The simulations were based on observed daily climatic data from 1990 to 2010 (30 years). These climate data sets were input into the SWAT model for simulating daily flows at numerous points along the basin's rivers. The output flows from the SWAT model were fed into the regulated flows and power production for different levels of hydropower development scenarios and different operation rules.

\subsubsection{Head assessment}

To assess potential hydraulic head along the river, computations were started at the main outlet of the watershed and then proceeded in the upstream direction. A location is identified as a potential hydropower site when a head of $20 \mathrm{~m}$ or more is available in a stream and the distance between the current location and the site immediately downstream exceeds $500 \mathrm{~m}$ (Kusre et al., 2010). A low-head hydropower application uses river current or tidal flows falling through $20 \mathrm{~m}$ or less to produce energy. This is to ensure that the tail race of the upstream site is not influenced by the reservoir of the downstream site. The assessment for the next potential site is carried out from the last selected site and the process continues to the upstream end of the river.

\subsubsection{Flow prediction}

The Arc-SWAT ArcGIS extension is a graphical user interface for the SWAT model (Sisay et al., 2017). The SWAT model is a river basin or watershed-scale model developed to predict the impact of land management practices on water, sediment and agricultural chemical yields in watersheds with varying soils, land use and management conditions over long periods of time. The SWAT model is physically based and computationally efficient, uses readily available inputs and enables users to study long-term impacts. To simulate discharge from the Arc-SWAT model, spatial inputs relating to the DEM, land-use/land cover map and soil map are required for the study watershed. Other inputs required for the model are long-term weather data and soil properties.

A 30-m resolution DEM and the land-use map for the area were supplied by the USGS and the land sat images classified by super vised classification system under in the ERDAS imagine software. The SWAT model also requires long-term weather data (rainfall, temperature, humidity, solar radiation and wind velocity) of some representative weather stations located in the vicinity of the study watershed and these were obtained from four weather stations. Finally by runiing the SWAT model to predict the simulated flow of the watershed area.

\subsection{3 criteria for site identification}

Minimum distance between two successive sites should not be less than 1000 meters in order to ensure that sufficient gap is present between the tailrace of one site and the diversion arrangement of the next site.

1. This also ensures that the river ecosystem will have sufficient time to rejuvenate.

2. A head of greater than or equal to 10meters, so that sufficient power is generated even for low flows.

3. Fourth and higher order streams having sufficient flow of water have been considered for selection of sites, as for lower order streams the flow is too less for generation of power 


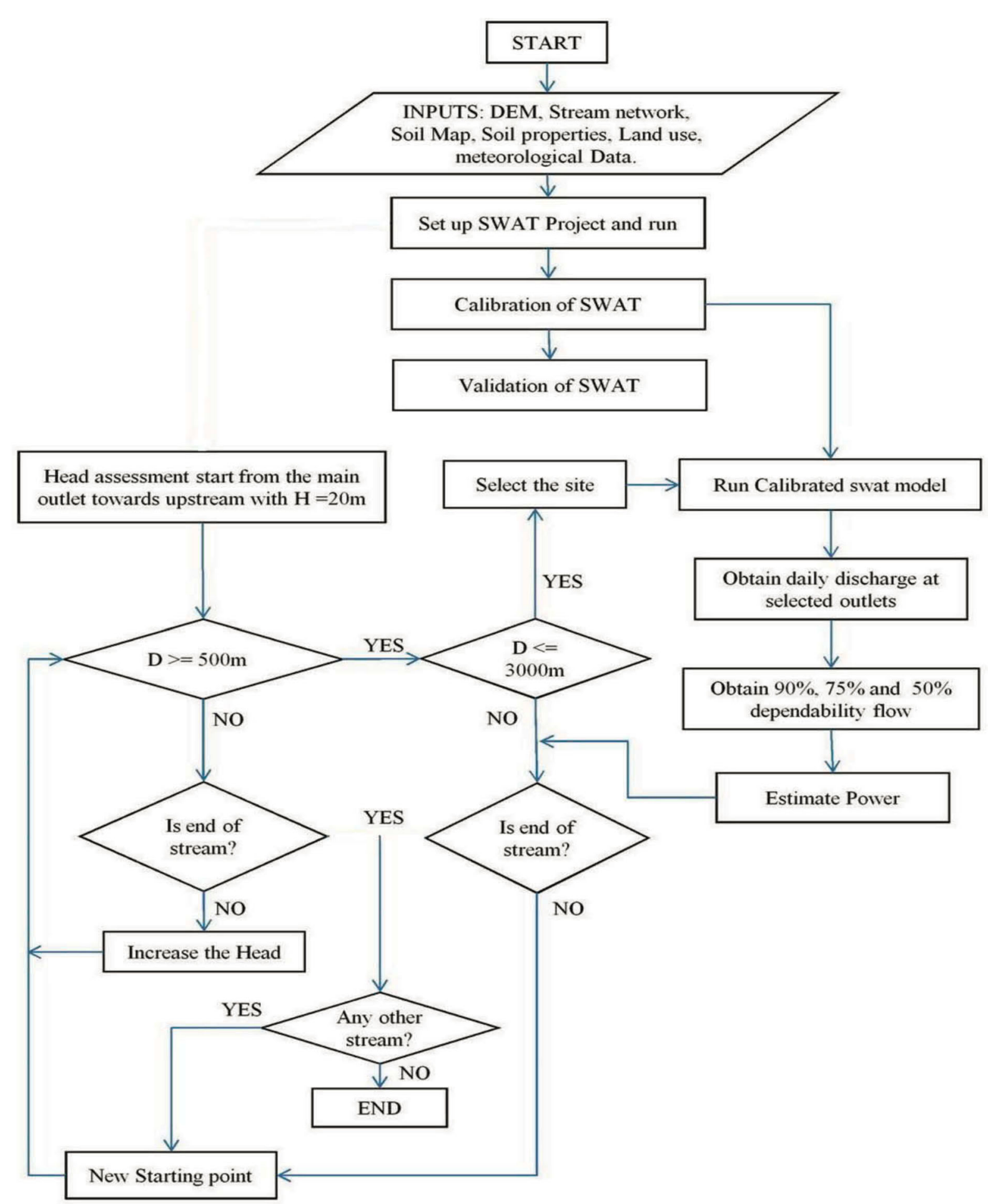

Figure 2.2 the assessment of potential hydropower by SWAT model, source (Pandey et al., 2015)

\section{Result and discussion}

\subsection{Sensitivity analyisis}

A careful study of input parameters and their sensitivity is required before calibration so as to identify which input parameters affect the output of the model most. 8 sensitive parameters were identified to have a significant influence in controlling the stream flow in the watershed 


\begin{tabular}{|l|l|l|l|l|l|}
\hline Rank & $\begin{array}{c}\text { Sensitive } \\
\text { parameter name }\end{array}$ & $\begin{array}{l}\text { Min. and } \\
\text { max. range }\end{array}$ & t-stat value & p-value & Fitted value \\
\hline 1 & CN2 & -0.2 to 0.2 & 2.77 & 0.00032 & 0.19 \\
\hline 2 & ALPHA_BF & 0 to 1 & 2.54 & 0.0057 & 0.11 \\
\hline 3 & SOL_BD & -0.5 to 0.6 & 2.34 & 0.013 & -0.22 \\
\hline 4 & SOL_K & -0.8 to 0.8 & 1.60 & 0.113 & -0.44 \\
\hline 5 & EPCO & 0 to 1 & -1.36 & 0.175 & 0.12 \\
\hline 6 & CANMX & 0 to 100 & -1.13 & 0.262 & 10.50 \\
\hline 7 & GWQMN & 0 to 2 & 1.00 & 0.316 & 1.49 \\
\hline 8 & REVAPMN & 0 to 0.25 & 0.434 & 0.665 & 0.02 \\
\hline
\end{tabular}

Table 3.1 senesetive parametrs

\section{2 flow Calibration and validation}

The watershed was divided into 21 sub basins which were further subdivided into 129 Hydrological response units (HRUs). A threshold value of 5\% for land use, soil and slope was specified for defining the HRUs. The flow duration curves developed for the identified potential sites and the final result of the study in the form of power estimates corresponding to $50 \%, 75 \%$ and $90 \%$ dependability, also explained by using the hydrogpah of the validated by the stream flow of the watserhed area.

Table 3.2 calibration and validation

\begin{tabular}{|l|l|l|}
\hline & $\mathrm{R}^{2}$ & ENS \\
\hline Calibration & 0.84 & 0.76 \\
\hline Validation & 0.78 & 0.73 \\
\hline
\end{tabular}




\section{FLOW_OUT_10}

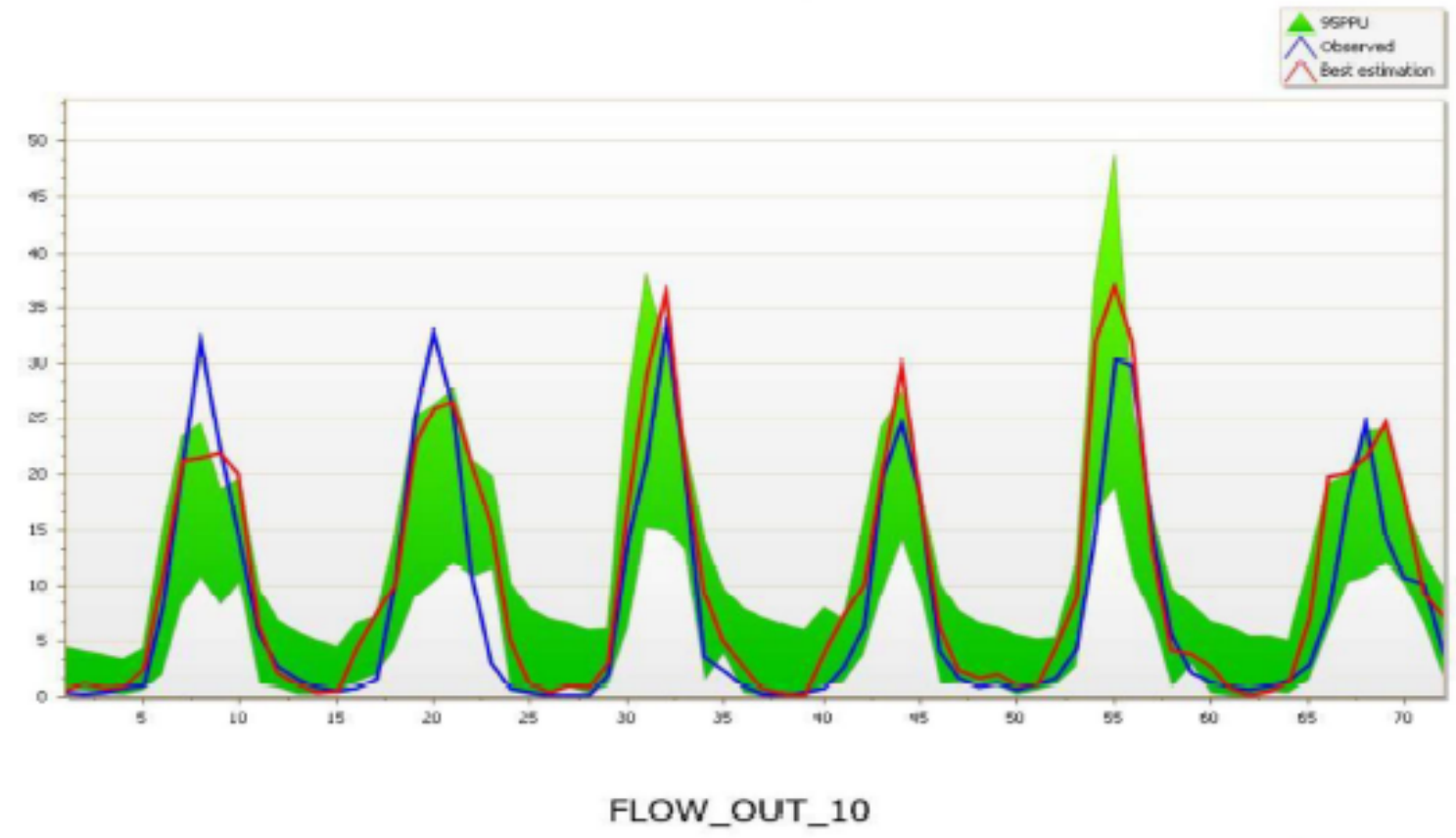

FLOW_OUT_10

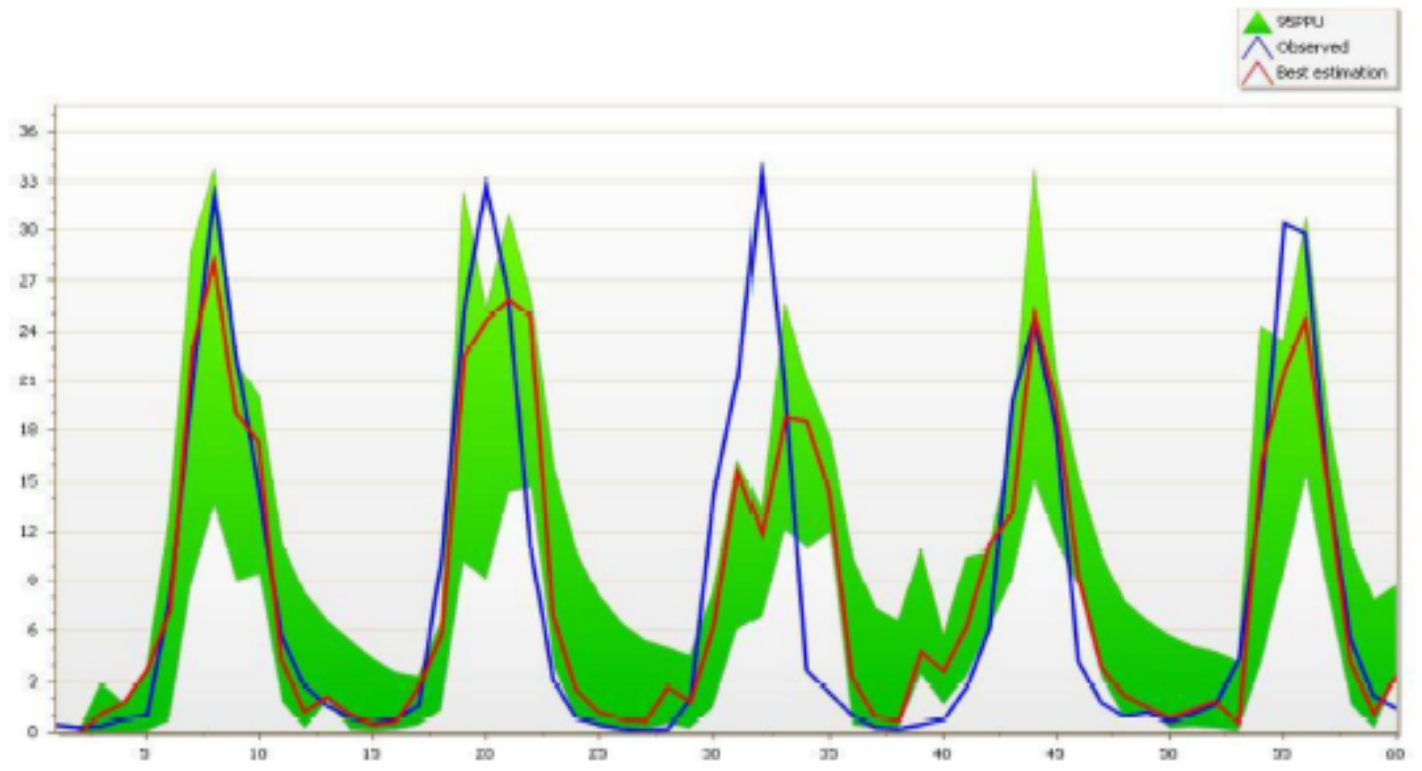

Figure 3.1 hydrographs of calibrated and validated flow 

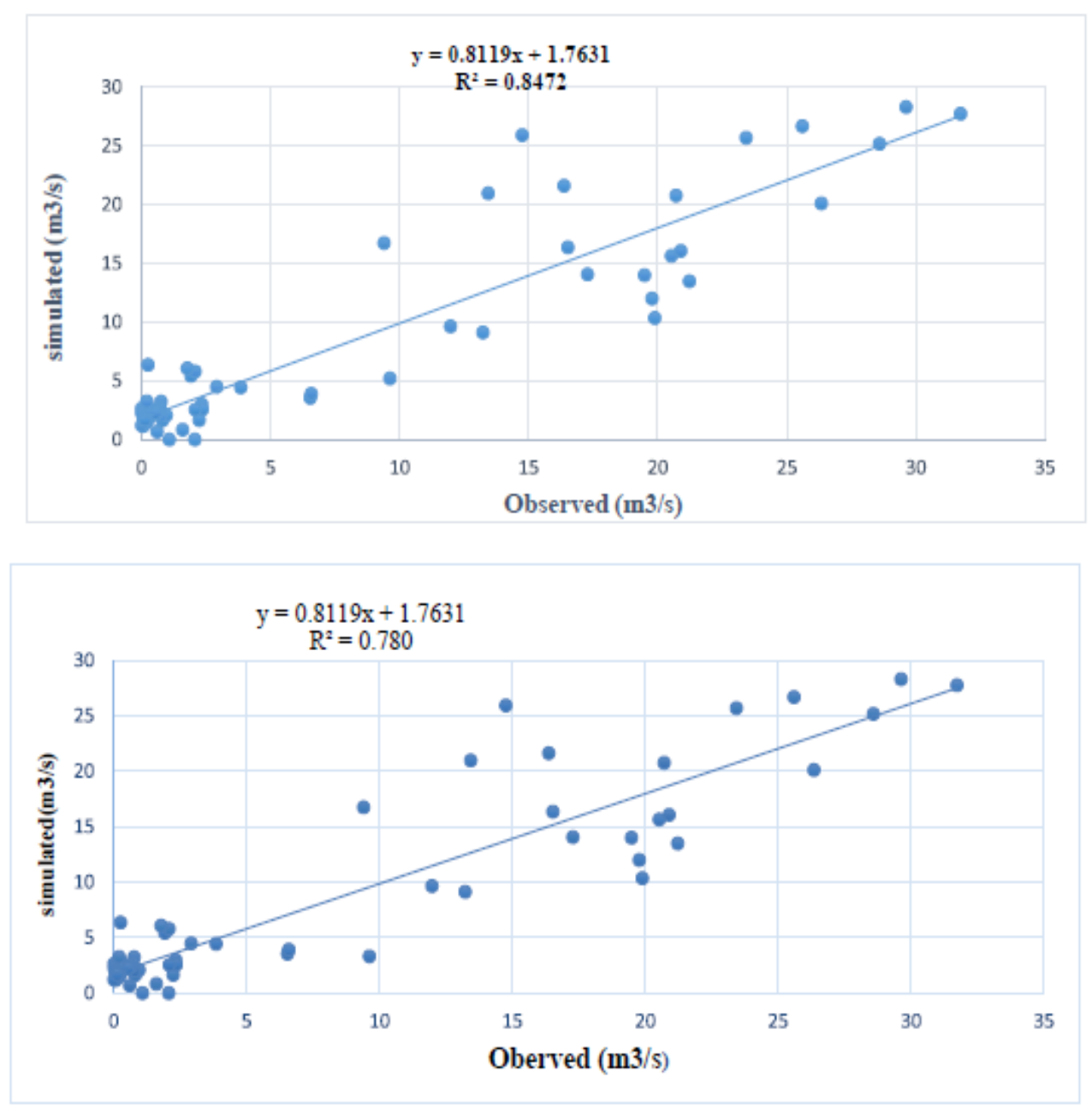

Figure 3.2 the scatter plot of calibration and validation period

\section{Identification of potential sites and estimation of}

hydropower potential A 30-m DEM was used to identify potential sites in the Temcha watershed. A site is identified as a potential site when a head of $20 \mathrm{~m}$ or more is available in the stream, with a separation of at least $500 \mathrm{~m}$ between two sites. The assessment for the next potential site is carried out from the last selected site and the process continued until the stream end; thus 33 potential sites were identified in the Temcha watershed and their locations along with the stream network are presented. It needs to be highlighted that, as well as hydrological, many other criteria (e.g. geological suitability, vicinity to important places) have to be met to finalize the site of hydropower projects.

The methodology presented here is a systematic way to identify potential sites from a hydrological angle and these sites could be further examined using other criteria to arrive at a different list. An optimization study could also be carried out by varying the norm for the head ( $20 \mathrm{~m}$ in the present case) and spacing $(500 \mathrm{~m})$ to develop an optimal basin development plan. The flow for a $90 \%$ dependable year (the year when flow has a $90 \%$ probability of exceedence) is used in the design of hydropower projects. The SWAT model was used to generate the flow for 30 years from 1990 to 2010 . The runoff was simulated for the main watershed outlet to identify the $90 \%$ dependable year, which was calculated by rearranging the annual runoff data in descending order and applying the Weibull formula (MNRE 2008).

This ensures that enough flow is available $90 \%$ of the time for hydropower generation. Once the $90 \%$ dependable year is found, the flow is generated separately for each selected potential site in the $90 \%$ dependable year. This makes it possible to have a more realistic knowledge of the potential flow, as both spatial and temporal changes in catchment features and inputs are taken into consideration by the model. The hydropower generation was estimated considering three levels of dependability, 90\%, 75\% and 50\% (MNRE 2008), resulting in a total hydropower generation capacity of 3039, 1127 and $805 \mathrm{~kW}$, respectively. 


\section{Conclusion and recommendation}

Conclusion

Use of SWAT model along with Arc GIS has been shown to be an effective tool in identification of suitable site for hydropower plants. This methodology will be especially beneficial for assessing the hydropower potential of Temcha catchments. A total of 20 potential sites were identified for runoff river plants in Temcha watershed under in upper blue nile basin tributaries, considering fourth and higher order streams with a minimum head criteria of $10 \mathrm{~m}$ and keeping the minimum distance between two consecutive sites as $1000 \mathrm{~m}$. The total estimated theoretical power potential was $12744 \mathrm{KW}, 2538 \mathrm{KW}$ and $603.1 \mathrm{KW}$ with $50 \%, 75 \%$ and $90 \%$ dependable flows respectively.

\section{Recommendation}

For the hydropower potential assessment they should have reatified certain tips to add values with that of particularl area selections.

During hydropower potential assessment further studies like, land use/cover change, river morphological analysis, hydrology of the area and other related issues should be done.

In this investigation several, tarcks were talked and some of those foused on the prioprity of the site condtion, inteventions of the socity, so they would be support by making a community service mechanismns and by ratifaing other projects to support the nearest living socity. ;

\section{Reference}

BARTLE, A. 2002. Hydropower potential and development activities. Energy policy, 30, 1231-1239.

DEUDNEY, D. 1981. Rivers of Energy: The Hydropower Potential. Worldwatch Paper No. 44, ERIC.

KUSRE, B., BARUAH, D., BORDOLOI, P. \& PATRA, S. 2010. Assessment of hydropower potential using GIS and hydrological modeling technique in Kopili River basin in Assam (India). Applied Energy, 87, $298-309$.

MATHI, R. S. \& DESMUKH, T. 2016. Spatial Technology for Mapping Suitable Sites for Run-of-River Hydro Power Plants.

PANDEY, A., LALREMPUIA, D. \& JAIN, S. K. 2015. Assessment of hydropower potential using spatial technology and SWAT modelling in the Mat River, southern Mizoram, India. Hydrological Sciences Journal, $60,1651-1665$.

SISAY, E., HALEFOM, A., KHARE, D., SINGH, L. \& WORKU, T. 2017. Hydrological modelling of ungauged urban watershed using SWAT model. Modeling Earth Systems and Environment, 3, 693-702. 